\title{
Editorial
}

\section{LA INCIDENCIA DEL MODELO DE EDUCACIÓN SUPERIOR Y DE LA INTERVENCIÓN ESTATAL EN LA CALIDAD DE LA EDUCACIÓN SUPERIOR EN COLOMBIA}

\author{
Juan Carlos Villalba Cuéllar (Editor) \\ Andrés González Serrano (Coeditor)
}

El reciente escándalo de la Universidad San Martín, y los no tan recientes casos de otras universidades, ponen sobre la mesa la discusión sobre el modelo de educación superior colombiano y la calidad que genera el mismo modelo. Se trata de un asunto de interés nacional porque el futuro laboral de la generación actual y de otras generaciones está en manos de ese modelo; y además se pone en juego la superación de la pobreza y la reducción de las desigualdades sociales, la competitividad de la mano de obra colombiana, y la generación de conocimiento que pongan al país en un lugar adecuado en el contexto internacional. Hay que señalar primero que los problemas de la educación superior en el ámbito universitario son de diversa índole, empezando por un bajo porcentaje de acceso a este nivel por parte de los estudiantes que se gradúan de bachillerato; un alto nivel de deserción pues uno de cada dos estudiantes no culmina sus estudios superiores (Melo, Ramos \& Hernández 2014); una insuficiente infraestructura física; problemas presupuestales y de asignación de recursos; una deficiente formación académica de sus docentes; una heterogénea calidad educativa; entre muchos otros. Para el ámbito de este editorial nos interesa aquella relativa a las causas y consecuencias de la heterogeneidad en la calidad de la formación otorgada por las instituciones que se encuentran en el nivel de educación superior de pregrado, así como la incidencia de la intervención del Estado en dicho fenómeno. En unas pocas líneas se pretende reflexionar sobre el modelo del sistema de educación superior actual bajo la hipótesis que el problema se centra en la lógica mercantilista que rige dicho modelo y en la falta de intervención del Estado.
Comencemos por el modelo de educación superior. La educación es el factor fundamental del desarrollo de la sociedad, de ella depende el paso de una sociedad con altos factores de incivilidad como la colombiana a una sociedad civilizada. El modelo colombiano de educación superior puesto en marcha desde hace muchos años le deja en gran medida a los particulares la responsabilidad de ejecutar esa tarea, ya que las universidades colombianas en un alto porcentaje son de carácter privado y los estudiantes (o sus padres) tienen la responsabilidad de financiar el pago de la educación, que además es muy costosa. La universidad pública, que tiene bajos costos de matrícula, juega un rol menor por su baja cobertura. Así las cosas, por razones históricas y políticas la educación superior en Colombia es de carácter predominantemente privado.

Bajo el esquema legal que las rige, las instituciones de educación superior (IES) se clasifican por el carácter académico en: a) Instituciones Técnicas profesionales; b) Instituciones tecnológicas; c) Instituciones universitarias o escuelas tecnológicas; y d) Universidades. El carácter de universidad lo pueden alcanzar las anteriores si cumplen con los requisitos del artículo 20 de la Ley 30 de 1992, desarrollados en el decreto 1212 de 1993 (Ministerio de Educación, página web). Estas IES pueden ser de naturaleza pública o privada.

Tal y como está diseñado el sistema, el Estado a través del Ministerio de Educación asume la supervisión y control de la educación superior, a través de una normatividad que le permite otorgar registros calificados (especies de licencias de funcionamiento de instituciones educativas $y$ 
programas) y ejercer unas funciones de posterior inspección, vigilancia y control del cumplimiento de unos mínimos estándares de calidad. Bajo este modelo en Colombia han surgido IES de todos los pelambres, gracias a que obtener un registro calificado de un programa resulta relativamente fácil. Encontramos así distinguidas IES con estándares de educación altos, creadas bajo modelos anglosajones o europeos, en algunas de las cuales parece que se enseñara y discutieran asuntos a espaldas de la realidad colombiana, verdaderas ínsulas, que además han formado a la clase dirigente del país con los resultados que hoy vemos. Igualmente existen universidades estatales de alta calidad, que tienen unos controles de acceso para el estudiantado que permite que solamente los mejores ingresen a ellas, creando otra especie de élite intelectual. Luego encontramos un montón de IES, las del montón, allí hay de todo, buenas, regulares y malas. Entre esta últimas algunas que no se sabe a qué se dedican, otras parecen factorías o fábricas de profesionales en serie, profesionales que al final de sus carreras han pagado altas sumas de dinero, si lo medimos por la capacidad de pago de los estudiantes, para obtener títulos que no les garantizan siempre ser profesionales competitivos en el mundo laboral, aunque existan destellos y casos aislados de aquellos que se esfuerzan por superar esta barrera y lo logran. También están aquellas que aunque las denominen "garajes" son administradas por gente seria y pretenden hacer las cosas bien. Encontramos otras que son el instrumento de renombrados gamonales regionales y locales para adquirir votos, verdaderas fábricas de votos cuyo lema podría ser: dame un voto y te daré un cupo en un "garaje". Existen otras que administradas por familias, parecen eso, sociedades de familia en que prima el reparto de utilidades (aunque su naturaleza jurídica diga otra cosa) y los intereses mezquinos del clan familiar que las dirigen. Otras IES también son la caja menor para financiar todo tipo de actividades, comerciales, políticas, etc. Y así, como "en botica”, hay de todo en el circo de la educación superior colombiana, un sistema maravilloso en que caben toda clase de mercachifles de la educación- negocio. La peor parte ese circo, la sufren los estudiantes y sus padres; estos últimos hacen enormes esfuerzos económicos porque sueñan con ver profesionales a sus hijos, dinero que en muchos casos se va a la basura, con el auspicio del Estado. Afirmamos esto porque la realidad del mercado laboral indica que un egresado de una universidad "de garaje" no es competitivo frente sus pares de otras universidades, y no tiene garantía de un desarrollo profesional adecuado. Los profesores universitarios igualmente sufren las consecuencias al ser usados por ese perverso sistema, ya que tienen que prestarse al juego de la mediocridad para no perder sus empleos o cátedras en las universidades-negocio. El resultado, un espectáculo de la peor calidad, el reflejo de la sociedad colombiana: una educación elitista, mediocre por convicción, que segrega y eterniza las diferencias en la sociedad colombiana, que no genera conocimiento, entre otros males. Porque el subdesarrollo no sólo es la falta de infraestructura como vías, parques, bibliotecas, hospitales, etc; el subdesarrollo más grave que puede padecer una sociedad es el subdesarrollo intelectual y Colombia bajo este modelo está sumida en ese hueco profundo. Este es el que se ha denominado el mercado de la educación superior, que mueve al año al menos 7,5 billones de pesos (El Tiempo, 16 de diciembre de 2014) y no pocos intereses políticos.

Partamos de lo fundamental, un país serio no debería tener universidades "garaje", eso es una vergüenza nacional, cle podría explicar usted a un ciudadano de un país desarrollado sin sonrojarse o sentir vergüenza por qué en Colombia existen este tipo de universidades? Pero lo que importa realmente es que nos expliquen a los colombianos por qué Colombia no cuenta con un sistema educativo democrático, incluyente, pluralista, en el que todo ciudadano tenga derecho a un cupo en una verdadera universidad por el solo hecho de vivir en suelo colombiano, más allá de cuánto dinero tiene y a qué casta pertenece. Y sobre todo educación de calidad, porque actualmente la calidad en la educación se mide por la capacidad adquisitiva de los estudiantes-clientes, si paga caro recibe buena calidad y si paga barato recibe mala calidad, 
con muy pocas excepciones como algunas universidades públicas. Un sistema con una lógica mercantilista que se aplica a la perfección para las mercancías, si compro zapatos baratos son de inferior calidad a unos caros. Pero esta lógica no se puede aplicar para un servicio que no es una mercancía, la educación es un derecho, un servicio público con una función social; además una simple razón práctica se impone, no puede tratarse como una mercancía un servicio del cual depende el futuro de una sociedad, es el peor de los negocios en términos del futuro de un Estado. Si la sociedad colombiana no se supera este estadio de atraso difícilmente el país logrará el bienestar de sus ciudadanos, ni será competitivo en el ámbito internacional. Además, en un contexto de post-conflicto mucho menos es viable encontrar la anhelada paz con un sistema educativo que perpetúa la desigualdad y la pobreza.

Ahora bien, ¿̇y qué papel ha jugado el Estado?, lo peor de todo es que el Estado y el Ministerio de Educación promueven ese sistema, otorgando registros calificados a diestra y siniestra; para luego cuestionar la calidad de los programas a los que ellos mismos les otorgaron los registros calificados.

Hace algunos años el MEN creó la figura de la acreditación de alta calidad, es un sistema que permite que a través de un sistema de auto -evaluación previo, el MEN certifique unos estándares de calidad educativa óptimos de los programas académicos y de las universidades. Este sistema sigue de todos modos una lógica mercantilista, porque se basa en el postulado de que en el mercado de la educación los agentes económicos (programas y universidades) se esforzarán por ser más competitivos, con mejor calidad académica, para acaparar más clientes-estudiantes, y este modelo de competencia generará la depuración del sistema. Con todo, el sistema ha dado frutos y ha contribuido a la mejora de la calidad académica de muchos programas, pero es un modelo que tiene debilidades, una de ellas es que de las muchas universidades y programas que existen en Colombia todavía en un alto porcentaje de ellas no importa para nada el tema de la acreditación de alta calidad, los tiene sin cuidado. Eso quiere decir, bajo la misma lógica, que el mercado tiene fallas, y que ciertas universidades tienen una posición de comodidad en su contexto que hace que tomen una actitud parasitaria (porque ni siquiera quieren competir), por ejemplo, si un gamonal o cacique regional tiene una universidad en provincia que le sirve para dar cupos a cambio de votos, qué tanto le interesará incurrir en sobrecostos para que esta institución tenga altos estándares de calidad y sea acreditada, muy poco o nada, claro está, pues tienen un mercado asegurado. En un país donde el Estado no es capaz de brindar el acceso a la educación superior a todos sus ciudadanos o a un número alto de estos siempre habrá mercado para los oportunistas. He allí el por qué una lógica mercantilista para un servicio que no es una mercancía no funciona, o tiene unos alcances limitados. Si desde la misma teoría de la competencia se creó la figura de la regulación es porque la competencia en los mercados no es perfecta, ni siquiera el postulado es completo en la teoría económica. Entonces se hace palpable la necesidad de cambiar el modelo, porque está basado en premisas inadecuadas y porque los resultados en Colombia son más que desastrosos.

Igualmente el Ministerio de Educación ha tenido iniciativas valiosas como "Ser pilo paga", con el fin de garantizar acceso a la educación superior y financiación de los estudios de estudiantes con alto rendimiento académico y escasos recursos. No obstante en un Estado social de derecho y conforme a nuestra constitución política hay una premisa que no puede ser olvidada, todos los ciudadanos tienen derecho a la educación, educación de calidad, y no solamente los pilos, pues seguimos bajo una óptica excluyente. Así que programas como estos son bienvenidos, pero deben ser complementados con políticas de ampliación de la cobertura y de la calidad de la educación pública universitaria. El fortalecimiento de la universidad pública en cobertura y calidad así como un estricto control del sistema educativo privado en educación superior deben 
ser complementarios. Algunos estudios demuestran que programas como "Ser pilo paga" tienen inconvenientes como fortalecer con dinero público el sistema de educación privado con alto precio para el Estado y en detrimento del fortalecimiento de la universidad pública (El Espectador, 18 de noviembre de 2015). Así las cosas, en un Estado social de derecho no ser tan pilo también debería pagar. Además surge una reflexión adicional, todos esos que "no son tan pilos" provienen en gran medida de la educación básica y secundaria pública o privada vigilada por el Estado, con graves deficiencias en su formación académica, el problema entonces es de raíz...

La instauración de las pruebas Saber Pro también se ha promovido como un mecanismo que sirva de filtro para garantizar la calidad de los profesionales que egresan de las IES. Pero el inconveniente es que imponer un examen estatal a los estudiantes de últimos semestres significa poner un manto de duda sobre la calidad de los profesionales de las IES, que se supone que tienen un registro calificado que garantiza una educación de una calidad estándar. Es un control que se torna además insuficiente y tardío, porque el resultado no mejora la calidad en la educación ni las condiciones del estudiante, sino que bajo criterios de evaluación que pueden ser cuestionables simplemente certificará la mediocridad o la brillantez del futuro profesional. Esto no resuelve nada de fondo.

Desafortunadamente el escudo que utilizan tanto Ministerio como IES para que lo narrado ocurra es "la autonomía universitaria", como si se tratase de una figura que sirve para justificar todo al interior de una institución educativa.

Hace poco el gobierno expidió como consecuencia del escándalo de la Universidad San Martín una ley que regula la inspección y vigilancia de la educación superior, la Ley 1740 de 2014, específicamente centrada en el aumento de las funciones de inspección otorgadas al MEN, como la posibilidad de establecer medidas preventivas frente a las IES, el control de información publicitaria y financiera de las mismas. Igualmente se contempla en la norma la creación de una Superintendencia de Educación que tiene que ser reglamentada en 2015 y que tendrá muchas funciones de las que ya tenía el MEN. La creación a las carreras de esta entidad burocrática es una ratificación de lo que venimos afirmando, de la aplicación de la lógica mercantilista a un sistema que no es mercantilista. Parece lógico que si los gobiernos de turno creen que la educación es una mercancía, a los problemas educativos le aplican soluciones de mercado, y eso fue lo que se hizo con esta ley de 2014, se fortaleció la regulación en el mercado de la educación. Ya sabemos que cuando un mercado presente fallas o es poco competitivo se debe acudir a darle poder al Estado para intervenir ese mercado y controlar a los agentes del mismo, para eso existen las comisiones de regulación y un papel complementario juegan las superintendencias en este objetivo. Y ahora el mercado de la educación tendrá su propia Superintendencia, bienvenida esta herramienta de regulación.

Sin embargo, esperamos que la intermediación de una Superintendencia no presente las problemáticas de otras superintendencias, por ejemplo, el hecho de que el Superintendente sea nombrado por el presidente puede implicar que esté sujeto a intereses políticos, los conflictos de intereses de sus funcionarios con universidades que les son afines, falta de un verdadero interés de control, entre otras.

A guisa de conclusión podemos decir que el modelo de educación superior en Colombia no garantiza los derechos constitucionales de igualdad y de acceso a la educación. El criterio de mercado y de competencia con que se edificó dicho modelo no logra la calidad en la educación, por el contrario, los resultados hasta ahora son desastrosos. La respuesta del Estado ha sido la regulación, una regulación liviana según Restrepo (2014), que ya existía y que se fortalece con la ley 1740 de 2014. Esperemos que funcione, pero no la consideramos suficiente si el Ministerio no mejora su nivel de intervención ex ante. En efecto, la intervención del Estado ha sido deficiente y tardía, bajo la complicidad del Ministerio de 
Educación se han creado IES y se les ha dado registro calificado a programas académicos que no garantizan una óptima calidad educativa. Así que si el Estado decidió dejar en manos de particulares una de sus principales tareas, por lo menos debería encargarse que esos terceros garanticen educación de calidad y no permitir que funcionen prestando un servicio educativo de baja calidad, lo cual de paso le sirve a cada gobierno de turno para engrosar las estadísticas de cobertura y mostrar falsos positivos en educación en sus rendiciones de cuentas. $\mathrm{Si}$ en Colombia hicieron carrera las universidades "de garaje" fue gracias la falta de intervención del Estado en la creación de dichas IES. Además, consideramos que el fortalecimiento de la universidad pública debe ser el eje central de cualquier política de mejoramiento de la educación superior en Colombia. Las IES de carácter privado deben jugar un papel complementario, con autonomía universitaria pero con alto grado de control, para evitar que se repitan caso como el de la Universidad San Martín. No obstante, programas como "Ser Pilo Paga", a pesar de ser valiosos, indican que la universidad pública no es la prioridad para el gobierno de turno. El sistema de educación superior de un país debe girar en torno a la universidad pública, eso es indiscutible. Pero desafortunadamente, hasta tal punto se desconoce o se ha caricaturizado el papel de la universidad pública que, hace poco algún directivo dijo que una prestigiosa universidad privada es la más pública de las universidades en Colombia.
Terminamos recordando que la cuestión no es de poca trascendencia, la consecución de una sociedad en que los ciudadanos tengan igualdad de oportunidades y posibilidad de acceso a una educación superior de calidad, sin distingo alguno, es un factor importante para que el país supere estadios de subdesarrollo y sobre todo para que se logre la anhelada Paz.

\section{Referencias}

El Tiempo, El lado oscuro de la educación superior, diciembre 16 de 2014.

El Espectador, Los alcances del "Ser Pilo Paga" son excesivamente limitados, noviembre $18 \mathrm{de}$ 2015.

Sí a la Superintendencia de educación, José Manuel Restrepo, El Espectador, 7 de marzo de 2015.

La educación superior en Colombia, análisis y estrategias para su desarrollo, Misas Arango Gabriel, Universidad Nacional de Colombia, 2004.

La educación superior en Colombia: situación actual y análisis de eficiencia, Ligia alba Melo, Jorge Enrique Ramos y Pedro Oswaldo Hernández, Borradores de economía, número 808, 2014, Banco de La República. 